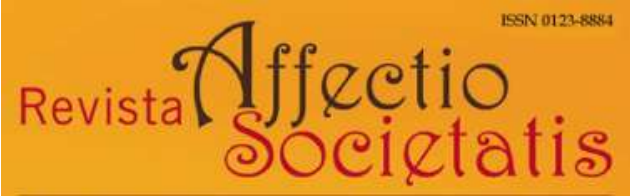

Departamento de Psicoanálisis | Universidad de Antioquia

Revista Affectio Societatis

Departamento de Psicoanálisis

Universidad de Antioquia

revistaaffectiosocietatis@udea.edu.co

ISSN (versión electrónica): 0123-8884

Colombia 


\title{
DO PARTICULAR AO UNIVERSAL: A FORÇA DO PERFORMATIVO NA SUBVERSÃO DO SUJEITO'
}

\author{
Cristina Moreira Marcos ${ }^{2}$ \\ Pontifícia Universidade Católica de Minas Gerais, Brasil \\ cristinammarcos@gmail.com \\ http://orcid.org/0000-0002-2481-2172 \\ Camila Ferreira Sales ${ }^{3}$ \\ Pontifícia Universidade Católica de Minas Gerais, Brasil \\ camilaferreirasales@gmail.com \\ http://orcid.org/0000-0002-6926-3197
}

DOI: 10.17533/udea.affs.v17n33a07

1 Trata-se de uma investigação sobre o conceito de ato analítico, tal como Lacan começa a formular no final da década de 60 , e sua relação possível com o conceito de ato performativo, conforme teorizado por Judith Butler

2 Psicóloga pela Universidade Federal de Minas Gerais (1987-1991), especialização em Saude Mental pela Escola de Saude de Minas Gerais (1993-1994), mestrado em Estudos Literários pela Universidade Federal de Minas Gerais (1995-1997), mestrado em Diplôme D'études Approfondies en Psychanalyse pela Université Paris 8 - Vincennes-Saint-Denis (1998-1999) e doutorado em Psychopathologie fondamental et psychanalyse pela Université Paris Diderot (1999-2005). É professora da Faculdade de Psicologia da Pontifícia Universidade Católica de Minas Gerais/PUC Minas desde 2003. Atualmente é Pesquisadora Mineira FAPEMIG, Docente Permanente e Coordenadora do Programa de Pós-graduação em PUC Minas, Brasil.

3 Psicóloga pela Universidade Federal de Minas Gerais/UFMG (2006-2010), especialização em Teoria

Psicanalítica pela UFMG (2011-2012), mestrado em Estudos Psicanalíticos pela UFMG (2014-2016).

Atualmente é Doutoranda no Programa de Psicologia Pontifícia Universidade Católica de Minas Gerais/PUC

Minas (início em 2019) e bolsista CAPES. 


\section{Resumo}

$\mathrm{O}$ presente trabalho se origina de pesquisa de doutorado em andamento na PUC - Minas. Trata-se de uma investigação sobre o conceito de ato analítico, tal como Lacan começa a formular no final da década de 60, e sua relação possível com o conceito de ato performativo, conforme teorizado por Judith Butler. Apresenta-se aqui a fase inicial da pesquisa, em que se intenciona mostrar a perfor- matividade como ato inaugural do sujeito. Assim, tanto para a psicanálise quanto para as teorias de gênero, $o$ ato performativo se instaura entre as categorias do universal e singular e opera com a subversão do paradigma da identidade.

Palavras-chave: ato performativo, psicanálise, teorias de gênero, universal, singular.

\section{DE LO PARTICULAR A LO UNIVERSAL: LA FUERZA DE LO PERFORMATIVO EN LA SUBVERSIÓN DEL SUJETO}

\section{Résumen:}

Este artículo es el resultado de una investigación doctoral en curso realizada con una subvención de Capes. Es una investigación sobre el concepto de acto analítico, que Lacan comenzó a formular a fines de la década del 60 , y su posible relación con el concepto de acto performativo, según la teoría de Judith Butler. Aquí se presenta la fase inicial de la investigación, en la que se pretende mostrar la perfor- matividad como acto inaugural del sujeto. Así, tanto para el psicoanálisis como para las teorías de género, el acto performativo se establece entre las categorías de universal y singular y opera con la subversión del paradigma de identidad.

Palabras clave: acto performativo, psicoanálisis, teorías de género, universal, singular. 


\section{FROM THE PARTICULAR TO THE UNIVERSAL: THE STRENGTH OF THE PERFORMATIVE IN THE SUBVERSION OF THE SUBJECT}

\section{Abstract:}

This article is the result of an investigation en doctoral research carried out with a Capes grant. It is an investigation on the concept of analytical act, as Lacan began to formulate at the end of the decade 60 , and its possible relationship with the concept of performative act, as theorized by Judith Butler. The initial phase of the research is presented here, in which it is intended to show the performativity as the subject's inaugural act. Thus, for both psychoanalysis and gender theories, the performative act is established between the categories of universal and singular and operates with the subversion of the identity paradigm.

Keywords: performative act, psychoanalysis, gender theories, universal, singular.

\section{DU PARTICULIER À L'UNIVERSEL: LA FORCE DU PERFORMATIF DANS LA SUBVERSION DU SUJET}

\section{Résumé:}

Ce manuscrit est le résultat d'une recherche de doctorat en cours avec le soutient de la Capes. Il s'agit d'une recherche sur le concept d'acte analytique, tel comme Lacan l'a conçu à la fin de la décennie 60 , et sa relation possible avec le concept d'acte performatif, tel que théorisé par Judith Butler. Nous présentons ici la phase initiale de la recherche, dans laquelle nous abordons la performativité comme acte inaugural du sujet. Il s'agit de démontrer que tant pour la psychanalyse que pour les théories du genre, l'acte performatif s'établit entre les catégories de l'universel et du singulier et opère avec la subversion du paradigme identitaire.

Mots-clés: acte performatif, psychanalyse, théories du genre, universel, singulier.

Recibido: 18/05/2020 • Aprobado: 14/07/2020 


\section{Do singular ao universal: a força do performativo}

\section{na subversão do sujeito}

O diálogo entre os estudos de gênero e a psicanálise convoca a uma discussão sobre o universal e o singular, categorias que se articulam à dimensão social e política da prática clínica e ao aspecto dialógico entre tais campos teóricos. Se, de um lado, as teorias de gênero subvertem o paradigma da representação identitária de sujeito, introduzindo o conceito queer para pensar a fluidez das performances de gênero, de outro a psicanálise também recusa uma figura positivada do indivíduo, não consentindo com a racionalização própria às ciências humanas e à psicologia.

O esforço que aqui se propõe é de pensar como as categorias do universal e singular são importante chave de leitura em ambos os campos teóricos para operar com a subversão do paradigma da identidade. Identidade que se estabelece na modernidade e que tem como figura central um sujeito dotado de razão, sujeito do Iluminismo. Stuart Hall, em seu livro A identidade cultural na pós-modernidade (2006), localiza a crise da identidade na modernidade tardia, quando ocorre o descentramento desse sujeito moderno, a partir da influência de autores de correntes teóricas importantes, como o marxismo, estruturalismo, a linguística de Saussure, bem como a teoria de Michel Foucault e os movimentos feministas dos anos 60.

O modelo de sujeito universal, cartesiano, que opera a partir da lógica da razão, sofre um "golpe narcísico" (Freud, 1996/1916-1917, pág. 292) quando Freud coloca ao lado dos achados de Copérnico e Darwin a descoberta revolucionária do inconsciente. Lacan, por sua vez, se utiliza da fórmula de Descartes, cogito ergo sum (penso, logo existo), para localizar o sujeito onde ele não pensa. "O que cumpre dizer é: eu não sou lá onde sou joguete de meu pensamento; penso naquilo que sou lá onde não penso pensar" (1998/1957, pág. 521). O que reafirma ao inconsciente seu estatuto subversivo, fora da racionalidade consciente, única admitida até então.

A teoria Queer, por sua vez, tece uma crítica ao feminismo dos anos 60 por sua insistência em manter a categoria da identidade. Judi- 
th Butler, filósofa expoente dessa teoria, ressalta que, na tentativa de questionar os papeis de gênero vigentes à época, o movimento feminista acaba por reforçar as categorias identitárias, endossando a norma binária e heterossexual. Nesse sentido, há algo em comum com a psicanálise, como nota Safatle: "Pois não devemos nos esquecer de como o século xx foi, à sua maneira, marcado pela transformação da reflexão filosófica sobre o sexual em setor fundamental para a crítica de certa concepção reificada de sujeito. O trabalho de Butler participa desta tradição" (2015, pág. 176).

Pretende-se pensar a subversão introduzida pela psicanálise e pelas teorias de gênero com base na reintrodução do singular a esse sujeito moderno universal, o que ocorre por meio de uma ação performativa. Na teoria de Butler, o ato performativo ganha estatuto de conceito para pensar as atuações do gênero fora da lógica de uma identidade essencialmente instituída. Se no campo da psicanálise o ato performativo não aparece como significante mestre, nem por isso a força subversiva do ato deixa de estar presente. É o que veremos adiante.

\section{A performatividade em Judith Butler}

Enquanto os feminismos dos anos 60 procuravam se fundamentar sobre um sujeito mulher, com reivindicações que garantissem à mulher igualdade na participação política, no acesso a bens e direitos e nas condições de trabalho, o movimento queer propõe uma revolução ao questionar profundamente a categoria mulheres. Judith Butler, filósofa expoente do movimento, considera que esse primeiro feminismo, ao reivindicar o direito das mulheres, acabou excluindo quem ele se propunha representar. Em seus termos:

Não basta inquirir como as mulheres podem se fazer representar plenamente na linguagem e na política. A crítica feminista também deve compreender como a categoria das "mulheres", o sujeito do feminismo, é produzida e reprimida pelas mesmas estruturas de poder por intermédio das quais se busca a emancipação. (Butler, 2016/1990, pág. 20). 
Tal crítica coloca em questão o conceito de representação, pois, para que determinada categoria seja devidamente representada, é preciso que se separe o grupo identitário que se pretenda representar. Essa separação provoca a exclusão de outras categorias, reforçando, paradoxalmente, as estruturas de poder que estão na base da estrutura social. Ao mesmo tempo, coloca-se em xeque a ideia de universalidade, dada a condição desigual em que os sujeitos são historicamente representados.

Joan Scott, em seu excelente artigo O enigma da igualdade (2005), trata a questão da igualdade como paradoxo, pois considera que a política é uma negociação constante entre os termos da identidade dos grupos e da diferença entre eles. As identidades de grupo são um fato social, o que leva a pensar que não há indivíduo puro, como uma entidade neutra e impassível, mas sim processos políticos e sociais que constituem esse indivíduo como um ser grupal (Scott, 2005).

Tais processos têm como efeito a diferenciação das identidades entre os diversos grupos e, consequentemente, a discriminação e exclusão de uns em detrimento do privilégio e ascensão social de outros. A igualdade como condição universal deveria pressupor que todos os indivíduos tivessem direitos iguais e o mesmo acesso aos meios de educação, cultura, saúde, etc. Isso permitiria que os indivíduos fossem tomados apenas como indivíduos e que isso bastasse. Não seria necessário evocar o grupo ao qual eles pertencem para reivindicar qualquer condição.

Na prática, sabe-se que isso não ocorre. A desigualdade faz com que nem todos tenham o mesmo acesso, sendo que aqueles que sofrem exclusão o sofrem por uma diferença - de gênero, raça, classe, por exemplo. Diferença em relação ao sujeito predominante, hegemônico, designado como o homem branco ocidental. Para Scott (2005), reconhecer que há uma diferença entre os lugares sociais que esse homem ocupa e os lugares destinados a outros sujeitos, com outros estereótipos, é nomear os grupos excluídos para eles sejam devidamente representados. Somente assim, colocando em destaque a diferença, se pode almejar a igualdade: esse é o paradoxo por ela apontado. 
No entanto, a ideia de representação incorre em múltiplas exclusões, como reforça Butler (2016/1990), pois destacar uma categoria identitária gera implicações políticas e normatizantes que podem ser violentas e segregadoras. Além disso, tais categorias são sempre referidas a uma norma heterossexual binária, como ela diz: "a regulação binária da sexualidade suprime a multiplicidade subversiva de uma sexualidade que rompe as hegemonias heterossexual, reprodutiva e médico-jurídica" (pág. 47).

A questão pode ser exemplifica com as campanhas de prevenção à AIDS nos anos 80 em que, ao definirem quais seriam os grupos vulneráveis ao contágio, geraram uma onda de preconceitos que terminou por patologizar e estigmatizar as homossexualidades. Miskolci (2011) aponta para o perigo do apelo identitário da organização política do movimento homossexual nos anos 70, que permitiu que os saberes médico-psi tomassem os sujeitos homossexuais como "uma verdadeira espécie" (pág. 48). Criou-se o paradoxo de um movimento que se dizia liberacionista, mas que era fundado na segregação de uma certa sexualidade. Enquanto os homossexuais reivindicavam o direito a uma sexualidade diferente, a sociedade utilizava justamente o argumento da sexualidade para excluí-los, por ser uma sexualidade fora da norma e da moral sexual da época. Assim, "o movimento homossexual se via enredado no dispositivo da sexualidade prometendo liberação ao mesmo tempo em que permitia que ele funcionasse" (pág. 48).

O paradoxo da representação, se assim o podemos nomear, torna-se complexo porque, para dissolver determinados preconceitos e estigmas, o movimento político precisa levantar a bandeira de uma causa, ressaltando os mesmos preconceitos e estigmas que pretende abolir. A perspectiva política da luta de classes, na tentativa de expansão da representatividade às minorias, sejam elas sexuais, raciais, classistas, etc., torna necessário o apelo às identidades para fazê-las visíveis, tangíveis, reconhecíveis.

No entanto, corre-se o risco de que os grupos, em suas aguerridas pautas políticas, acabem reforçando os contornos identitários universais que tornam todos daquele grupo iguais, desconsiderando-se as diferenças entre eles. Além disso, o apelo positivista à identidade dei- 
xa de fora a contingência daquilo que aparece no percurso e que vem problematizar o conjunto fundado num regime universal, deixando pouco ou nenhum espaço à dimensão de negatividade da identidade, ou seja, ao que faz furo no saber identitário.

Tendo isso em mente, Butler introduz no movimento feminista uma crítica às categorias da identidade que as estruturas jurídicas contemporâneas engendram e naturalizam. Como já foi dito, tais categorias sugerem que o sujeito mulheres é estável e coerente, desconsiderando que sua origem é fundada numa matriz heterossexual à qual a própria linguagem está submetida. A estabilidade da categoria não permite o avanço dos objetivos feministas, sendo que, para que haja alguma transformação, é preciso primeiramente questionar a noção de identidade que se imiscui nas relações de gênero.

Para tal, é necessário desmistificar a diferença sexo/gênero, entendendo que colocar a dualidade do sexo numa lógica pré-discursiva é uma das maneiras de manter a estabilidade interna e a estrutura binária sobre a qual se assenta a categoria de identidade. Em seus termos: "essa produção do sexo como pré-discursivo deve ser compreendida como efeito do aparato de construção cultural que designamos por gênero" (Butler, 2016/1990, pág. 28). Assim, a proposta ética e política de Judith Butler pressupõe uma subversão da categoria de identidade, como sugere o título do seu livro Problemas de Gênero: Feminismo e Subversão da Identidade, já que, enquanto categoria fixa, tal noção acaba por ignorar a pluralidade do termo mulheres e estagnar os avanços de uma política representacional.

É preciso se libertar, segundo ela, da necessidade de construir uma base única e consistente para a teoria feminista, como o fazem as posições a favor da identidade ou mesmo da anti-identidade. Em sua perspectiva, não há um sujeito do feminismo, já que tanto feminilidade quanto masculinidade são processos regulatórios de repetição, normas internalizadas sob a forma de estilo corporal. A representação ou teatralização repetida de um gênero é o que ela chama de ato performativo:

O gênero não deve ser construído como uma identidade estável ou um locus de ação do qual decorrem vários atos; em vez disso, o 
gênero é uma identidade tenuemente constituída no tempo, instituído num espaço externo por meio de uma repetição estilizada de atos. (Butler, 2016/1990, pág. 242).

A performatividade de gênero é a possibilidade discursiva que, em contraponto à suposta fixidez biológica, amplia o leque de alternativas genéricas para além do binômio feminino/masculino. Disso decorre que sua pretensão política não é pautada na noção de identidade, pois falar em identidade pressupõe características universais e biológicas, ignorando que há uma regulação sobre os corpos que é criada pelo poder. Falar sobre gênero, portanto, já é produzir, através do discurso, a diferença entre os sexos que é tida como natural. Historicamente, essa diferença tem se constituído com base numa violência imposta aos sujeitos, quando estes são impelidos a assumir uma das duas posições binárias - homem ou mulher -, as únicas a terem visibilidade e inteligibilidade social.

A origem do termo performativo na obra de Butler vem do filósofo da linguagem britânico John Langshaw Austin, que, a partir da desconstrução do par verdadeiro-falso, propunha uma discussão sobre os enunciados que não são verdadeiros nem falsos, que não descrevem nem informam, mas que fazem algo. Usando o verbo perform, ele argumenta contra a premissa filosófica de que usamos a linguagem para dizer o que é verdadeiro ou falso. Em sua concepção, o ato performativo "indica que a emissão da declaração é a realização de uma ação" (Austin, 1962, como citado em Spitzner, 2017, pág. 7).

Butler (2006/1990) se apropria do termo para interrogar como se faz e desfaz o gênero com palavras. Ela propõe pensar os atos performativos como atos corporais e práticas significantes que produzem corpos sexuados e identidades de gênero através da repetição. Com isso, ela denuncia a ilusão da naturalização dos corpos e também a metafísica da substância que afirma a existência de uma essência, sugerindo, ao contrário, que os corpos são efeitos de discursos, por sua vez produzidos pelo poder.

A performatividade, nessa perspectiva, é "o poder reiterativo do discurso para materializar o corpo, os outros objetos que o restringem e 
controlam, através do processo de citação das normas" (Spitzner, 2017, pág. 9). Para Butler, o poder não é originário de um sujeito, tampouco de um desejo, mas é uma reiteração, uma ação repetitiva que constitui a materialidade do corpo. Ela propõe: "consideremos o gênero, por exemplo, como um estilo corporal, um 'ato', por assim dizer, que tanto é intencional como performativo, onde 'performativo' sugere uma construção dramática e contingente do sentido” (2016/1990, pág. 240).

A filósofa também dialoga com Jacques Derrida para transpor o gênero e o corpo à lógica da repetição como alteração constante sem origem. Pois é a ideia de origem que deturpa a possibilidade de compreender os reais processos históricos e suas lógicas discursivas. Ela critica a ideia de um eu fenomenológico anterior ao discurso, pois "a invocação performativa de um 'antes' não histórico torna-se a premissa básica a garantir uma ontologia pré-social de pessoas que consentem livremente em ser governadas, constituindo assim a legitimidade do contrato social" (2016/1990, pág. 20).

Ou seja, a defesa de uma categoria de sujeito pura, descontextualizada historicamente, como se houvesse um antes temporal, é uma estratégia da própria lei para legitimar sua validade. Seria como um fundamento fictício para afirmar o sujeito em seu estado natural, universal, sem considerar que ele próprio fora criado pelas estruturas jurídicas do liberalismo clássico. A noção positivista da identidade, que por muito tempo alimentou uma teoria positiva da ação política, tende a ignorar o fato de que os sujeitos que subvertem as normas são eles próprios produtos do poder e atravessados por ele. A categoria foucaultiana de poder serviu a Butler para advertir o movimento político a passar das identidades sexuais como representações dentro da estrutura binária dos sexos (tal como propõe o estruturalismo) a uma teoria performativa do sexual.

Vladimir Safatle, em comentário ao livro Relatar a si mesmo: crítica da violência ética, de Judith Butler, diz que, se a representação advoga a favor de uma estereotipia de gênero, a performatividade já possibilita a realização de "atos subjetivos capazes de fragilizar o caráter reificado das normas, produzindo novos modos de gozo que subvertam as interdições postas pelo sistema binário de gêneros" (2015, pág. 
186). Em sua empreitada subversiva, a teorização de Butler localiza aquilo que tensiona a norma, como os corpos abjetos. Tais são os corpos dotados de uma singularidade que interroga a norma - sendo, por isso, ininteligíveis, a exemplo dos transexuais - e que convoca à subversão do valor universal da representação, justamente por não se adequarem àquilo que é contemplado pelo discurso normativo. Isso indica que a teoria queer questiona a lógica universal a partir do singular, ou seja, do irrepresentável.

O movimento queer tem possibilitado avanços tanto no campo prático quanto no programa teórico de pensadores do feminismo e pós-feminismo, tanto na polis quanto na academia. Podemos citar, por exemplo, a inserção de mulheres e pessoas transgênero em cargos públicos, a visibilidade da comunidade trans nos veículos de comunicação alternativos à grande mídia, o questionamento social da lógica binária nos espaços públicos (por exemplo, a divisão binária de banheiros), a legitimação do nome social, etc. Ainda falta um longo caminho a ser percorrido, mas não se pode ignorar as conquistas até aqui adquiridas.

Vejamos em que aspectos esse programa teórico dialoga com a psicanálise em se tratando do performativo como modo de inscrição do singular sobre o universal.

\section{O sujeito da psicanálise entre 0 singular e 0 universal}

A psicanálise, em seu surgimento, lança sobre o setting da psicologia, sob domínio até então da experimentação behaviorista, por um lado, e da análise filosófica, por outro, um novo paradigma do sujeito humano. Freud aposta sua subversão na lógica do inconsciente, comparando sua descoberta às de Copérnico e Darwin. Ao dizer que o eu "não é senhor nem mesmo em sua própria casa" (Freud, 1996/19161917, pág. 292) e que cabe aos médicos que venham se interessar pela psicanálise "contentar-se com escassas informações acerca do que acontece inconscientemente em sua mente" (pág. 292), ele fere a expectativa consciente de dominar o campo do comportamento hu- 
mano, inserindo uma nova forma de causalidade psíquica entre as conhecidas até então.

Safatle (2012) ressalta que em Freud "o sujeito deixa de ser uma entidade substancial que fundamenta os processos de autodeterminação para transformar-se no locus da não-identidade e da clivagem" (pág. 12). Ao afirmar a existência do inconsciente, a psicanálise se afastou da lógica racional, determinista e voluntarista do indivíduo, a fim de se ocupar daquilo que há de mais singular: o desejo do sujeito.

O desejo em psicanálise nasce da inexistência de uma satisfação completa, universalmente dada, que nos levaria a criar uma totalização do saber sobre a sexualidade. A inscrição sexual no corpo, como Lacan retoma em Freud, é da ordem de um enigma e não pode ser apreendida totalmente pelo sentido. Jeferson Pinto nos lembra que "não é possível fazer um Todo da sexualidade (a partir de traços positivos, é claro, porque não encontramos ninguém que diz não a ela) e é exatamente por aí que se introduz a contingência" (2008, pág. 114).

Relembrando o mito de Totem e Tabu, notamos que Freud recorre ao Pai Primevo como figura de exceção para falar da fundação da lei universal. A partir de Um que detém o falo e cujo gozo é ilimitado, a sociedade se organiza em torno da proibição do incesto que passa a regular o gozo e universalizar a existência. Trata-se da universalização da função fálica a partir da metáfora paterna, esta que funda o inconsciente na conjunção de dois significantes, o Nome-do-pai sobre o Desejo da mãe (NP/DM). Introduz-se entre os significantes a existência de um real, pois o deslizamento do significante sobre o significado indica que são possíveis inúmeros sentidos. "É exatamente porque cada palavra do binômio conjugado pode ter vários sentidos que essa conjugação fisga um real" (Vieira \& Barros, 2015, pág. 23).

Tal operação metafórica não é puramente abstrata. Ela produz a materialidade do corpo, pois para Lacan o significante é de ordem material. Comparada à religião e à ciência, é a causa material que está em jogo na psicanálise: "essa causa material é, propriamente, a forma de incidência do significante como aí eu defino" (Lacan, 1998/1966, pág. 890). O efeito da metáfora incide sobre o real do corpo e consti- 
tui o sujeito como ser sexuado a partir da metaforização de um real primordial (Vieira \& Barros, 2015). Portanto, se a metáfora paterna enlaça a lei e o desejo, localizando o sujeito no lugar da incógnita, entre o desejo da mãe e o nome-do-pai, ela é uma articulação necessária, e não contingente.

Por outro lado, há o campo daquilo que Lacan nomeia como Outro gozo, o gozo feminino, e que não se atém à ordenação regida pelo falo. Ali, a exceção aparece de forma imprevisível, pois não há essência ou delimitação. Como explica Pinto, "a exceção aqui é diferente daquela que caracteriza o Pai Primevo, uma exceção definida, pois se trata de uma existência indeterminada" (2008, pág. 114). Isso subverte a perspectiva clínica, pois não se trata mais (ou apenas) de interpretar a cadeia significante, mas entra em cena o ato analítico que leva em conta essa existência indeterminada. Em outros termos: "uma infinitude do gozo que não se assemelha ao universo fechado da função fálica, mas que a 'parasita' e nela se faz presente" (pág. 114). É essa a dimensão contingente da pulsão: o que não se deixa capturar pela lógica universal da argumentação e que define o modo particular de inserção do sujeito na linguagem.

Esse particular interessa à psicanálise na medida em que o real é convocado a romper com a universalização à qual tende o imaginário, e com ele o significante, na tentativa de criar uma referência identitária que sirva de amparo ao sujeito. Lacan, observando isso, propõe a inversão da lógica aristotélica entre o universal e o particular. Enquanto, para Aristóteles, a proposição universal tem caráter fundante, da qual se extrai a particular que reafirma ou contradiz a universal, para Lacan é a proposição particular que funda a universal. A fundação da comunidade humana, com base no mito de Totem e Tabu, decorre justamente do ato de assassinar o pai, única exceção à regra, a partir do qual se funda o universal da comunidade fraterna e da lei que interdita o incesto.

Assim, foi a partir de um caso particular (o assassinato do pai da horda) que se pôde instituir a lei universal (interdição ao incesto). Teixeira, no texto $O$ alicerce contingente do Universal, explica que Lacan oferece um modo inédito de pensar o universal: "ao inverter a hierarquia em 
vigor na subalternação da particular pela universal, a ênfase recai na dimensão declarativa do sujeito como constituinte da necessidade lógica" (2010, pág. 134). O que significa que a necessidade do sujeito se funda sobre a contingência do traço particular, a partir de uma declaração performativa que, esta sim, institui a classe universal (e não o contrário).

Deduz-se disso que a classe universal não pressupõe uma essência, uma existência pré-determinada, como se pode entender a partir da lógica aristotélica. Não se pode tomar o universal como um dado sempre presente, mas sim como "efeito de consideração da exceção que vai introduzi-lo" (Teixeira, 2010, pág. 132). A torção lógica que Lacan opera faz predominar justamente o ato de enunciação do sujeito sobre aquilo que está supostamente pré-determinado. Tal ato, segundo Teixeira, tem a qualidade de uma violência performativa, assim como foi o parricídio, que funda retroativamente o universal.

A proposição universal supostamente atemporal de Aristóteles, portanto, se distancia do estatuto ontológico a priori para ganhar, em Lacan, uma "eficácia real enquanto efeito a posteriori engendrado, numa temporalidade lógica, pela violência da função declarativa" (Teixeira, 2010, pág. 131). Disso se constata que somente as proposições particulares dizem da dimensão da existência, enquanto as universais permanecem como abstrações sem efetividade por não levarem em conta o engajamento existencial do sujeito que as enuncia.

Essa problemática é ilustrada no seminário XV sobre o ato psicanalítico, quando Lacan observa que o comandante da tropa não causa efeito espantoso ao proferir o slogan universal todo soldado deve morrer pela pátria. Já quando ele diz a particular algum soldado deve morrer pela pátria, a reação é de espanto e medo. O que indica, segundo Teixeira (2010), que a premissa lógica dedutiva da universal para a particular não é tão simples assim. A decisão do sujeito sobre morrer ou não pela pátria faz a diferença, e não querer morrer pela pátria pode gerar o enunciado performativo que fura a universalidade da primeira assertiva e instaura outra realidade, em que não todos morrerão pela pátria.

Desse modo, se a proposição universal é puramente abstrata, uma vez que não remete a nada existente, mas se torna enunciado 
discursivo fundado sobre si mesmo, a possibilidade existencial do sujeito está condicionada à contingência, ao ato performativo, ou ainda, à dimensão declarativa do discurso. É por esse viés que a psicanálise localiza o surgimento do sujeito no campo do Outro, sujeito este barrado e que não pode ser universalizado, uma vez que a experiência da sexualidade o amarra numa relação singular ao próprio gozo.

Faz-se mister esclarecer que os termos particular e singular comportam uma diferença sutil. A singularidade não remete unicamente ao que ensina o caso clínico em psicanálise. Pinto (2008) fornece uma excelente discussão a esse respeito. Segundo ele, a singularidade diz respeito à imprevisibilidade, na medida em que os predicados de determinada classe de saber são inoperantes quanto à sua previsão. Se fosse possível prever a singularidade, sua manifestação seria apenas um caso particular de uma classe. Sendo assim, os predicados seriam capazes de enquadrar o sujeito como exemplo de uma classe.

Ou seja, a singularidade se evidencia como exceção em relação à totalidade do saber e, no momento mesmo em que se revela, torna paradoxal a classe à qual deveria pertencer como um caso particular. Pinto (2008) afirma que quando um analista faz um diagnóstico de histeria ele é guiado menos pelos indicadores de um saber universal do que pelo modo particular com que aquele paciente se distingue dos outros. Somos guiados mais pelo modo particular como gozo e significante se articulam para aquele sujeito do que por um saber teórico universal válido para todos os sujeitos histéricos.

Dessa maneira, pode-se dizer que o singular é aquilo que faz furo no particular, inserindo um dado de novidade ao particular já existente. Se o particular funda o universal, conforme visto acima, formando uma exceção no regime universal sobre o qual se extraem novos particulares, o singular é o que permite que o saber particular não seja universalizado. Ele pode ser considerado, pois, a mais subversiva das categorias, não se deixando apreender pela totalização pretendida pelo particular ou pelo universal.

É a isso que Miller (2003) se refere quando diz que, se privilegiamos o caso singular, ou seja, o detalhe, o não-generalizável, é na 
medida em que não acreditamos mais nas classes dos sistemas de classificação. Miller denomina como universal negativo a regra universal da espécie dos sujeitos sob a qual cada analisante inscreve seu caso, na medida em que se refere à ausência de uma regra, à ausência de um programa sexual que Lacan designou como não relação sexual. "É o único universal que vale para um sujeito, porém é um universal negativo que significa a ausência de uma regra (...). O sujeito é sempre obrigado a inventar seu modo de relação ao sexo sem ser guiado por uma programação natural" (pág. 20). Com seu modo singular de responder à não existência da relação sexual, ou seja, com seu sintoma, o sujeito é sempre uma exceção à regra e "seu sintoma é sua invenção ou reinvenção da regra que lhe falta" (pág. 23).

\section{Para-além do nome: o gozo como subversão da subversão}

Diante do que foi exposto, retomemos a discussão sobre as identidades no campo da psicanálise e das teorias de gênero. Sabe-se que o Outro para a psicanálise não pode ser reduzido aos determinantes culturais e de linguagem que dotam o sujeito de uma identidade neutra e estática, a qual podemos chamar de universal. Trata-se de um Outro que, de maneira singular, encarna as figuras que veiculam um desejo diante do qual cada sujeito se posiciona (Fajnwaks, 2015). A experiência da sexualidade, para a psicanálise, não pode jamais ser universalizada. Embora o sujeito se utilize de significantes da cultura para se localizar de um lado ou de outro da diferença sexual, sendo nomeado e nomeando a si próprio como feminino ou masculino, a lógica binária é insuficiente para significantizar o corpo sexuado.

Isso porque se, por um lado, a cultura tem a função de ordenar o gozo, dando um direcionamento coletivo às pulsões (o que Freud chamou de sublimação), por outro a experiência sexual propriamente dita não se conforma à regra do significante. Se o corpo sexuado ganha seu nome do Outro, nomeação que é ancorada na lógica fálica, isso não o torna totalmente passível de ser nomeado: depara-se com a impossibilidade do sentido pleno, pois há o encontro com a verdade da inexistência da relação sexual. 
Como explica Pedro Ambra, "toda nomeação carrega em si o horizonte de sua própria contingência, dado que a mensagem é uma colisão relativamente arbitrária entre o discurso e o caráter constelacional (e, portanto, não substancial) do significante" (Ambra, 2017, pág. 245). Nesse sentido, o corpo sexuado é nomeado sempre de modo contingencial, "numa operação de alienação na qual o sujeito se oferece como resposta ao lugar que supõe corresponder à anatomia no discurso do Outro" (pág. 286). Anatomia, vale ressaltar, que diz respeito mais ao semblante do que propriamente à fisiologia.

O desvendamento de Freud sobre a vida sexual infantil nos deixa o legado disso que é a dimensão mais singular do sujeito. Não nos cabe esquivar dessa descoberta, posicionando a psicanálise em um viés normativo ou biologizante - o que teóricas do gênero acabam por fazer, ao debaterem com a psicanálise. A questão central da identificação, para a psicanálise, parte do momento do júbilo especular quando a criança se vê refletida no espelho, o que marca a alienação fundamental do sujeito que se vê constituído como Outro, ou como gozo do Outro. Este gozo está além ou aquém da linguagem, portanto não é inteiramente redutível à lógica fálica, o que significa que os enquadramentos normatizantes de gênero só se prestam a reduzir essa experiência satisfatória de júbilo a uma anatomia essencialista.

Sendo assim, a sexualidade não pode ser nomeada com base apenas na experiência genital. $\mathrm{O}$ atravessamento da imagem por esse gozo não fálico coloca um impasse na nomeação do ser sexuado, já que aponta para a inexistência de uma relação equivalente entre nome e corpo, denunciando o caráter insuficiente do significante diante do corpo em movimento. O que significa dizer que o corpo sexuado para o sujeito da psicanálise é da ordem de um enigma, pois é sempre atravessado pelo desejo. Desejo que tem "o caráter paradoxal, desviante, errático, excentrado e, até mesmo escandaloso, pelo qual ele se distingue da necessidade" (Lacan, 1998/1958, pág. 697).

Em seu texto Psicologia das massas e análise do Eu: uma teoria do final de análise?, Pinto (2008) destaca a estratégia freudiana de tomar a satisfação pulsional como critério de singularidade em oposição à exigência de conformidade ao grupo. Pensar os efeitos de uma análi- 
se a partir da lógica coletiva implica interrogar sobre o fim de análise, quando o analisando se desloca da posição de objeto do Outro e passa a se identificar como sujeito. A relação do sujeito com o líder levanta a hipótese de que quem busca análise procura, em última instância, um mestre. Ele supõe que ali reencontrará a resposta para o que lhe falta, resposta esta que o colocaria na condição de uma conformidade em relação a determinada situação social. Busca-se, então, o conforto pela alienação no analista.

Porém, a psicanálise não busca o amor civilizador, como propõem outras práticas, pois as exigências do inconsciente são de um saber sem sujeito. A transferência se orienta pelas marcas do objeto $a$, que comanda a operatividade do desejo. Há uma diferença entre indivíduo e sujeito: enquanto o primeiro está misturado ao grupo, massificado, o segundo, a partir do desejo, encontra sua autonomia. Por isso o trajeto da análise vai da alienação no campo do Outro, movida pelo amor, à separação que o torna singular (Pinto, 2008).

Fajnwaks, em artigo no qual propõe uma discussão da psicanálise com as teorias de gênero, diz que o termo identidade não é um conceito psicanalítico, portanto não há, para a psicanálise, a tentativa de promover novas identidades. A diferença sexual interessa por partir da relação do ser falante ao gozo: “... quer seja a partir de um conjunto fechado, totalizante, unificante, a partir do Um que se repete na relação com a satisfação fálica, ou bem a um gozo que se abre a um ilimitado, que ex-siste àquele Um fechado" 4 (Fajnwaks, 2015, pág. 32).

Esse Outro gozo que não se atém ao reino universalizante age retroativamente sobre o conjunto do $U m$, provocando a ruptura dessa totalização. A análise se volta sobre esse gozo não-todo, marcando nele a força do singular contra as tendências identitárias do imaginário. Dessa maneira, pensar o gozo como índice da diferença sexual implica a responsabilidade de se atentar à singularidade do desejo, de

4 Tradução livre do trecho: “...que ce soit à partir d'un ensemble fermé, totalisant, unifiant, à partir d'un Un qui s'itère dans le rapport à la satisfaction phallique, ou bien à une jouissance qui s'ouvre à un illimité, qui ex-iste à cet Un fermé". 
interpelar a clínica psicanalítica a partir do desejo, e não a partir da noção de identidade que é convocada pelo significante gênero.

A tentativa de nomeação das identidades sexuais pelos discursos de gênero, que se diversifica em correspondência aos inumeráveis tipos de identificação e orientação sexual, se difere da nomeação produzida pela psicanálise, cuja interpelação se direciona ao real do gozo pelo sintoma produzido em análise. Assim:

Essa nomeação [em análise] é constituída como tal a partir de um processo de desidentificação do sujeito com os núcleos condensadores de gozo no coração dos sintomas, e neste sentido, ela opera exatamente no sentido oposto às identificações que se produzem a partir do gozo sexual promovido pelas culturas queer. (Fajnwaks, 2015, pág. 31)

Apesar dessa crítica, reconhece-se que a problemática das identificações também preocupa muitos teóricos queer. Na perspectiva sócio-política, a dicotomia entre igualdade e diferença faz perceber que o conceito de representação é marcadamente paradoxal. Para se ter igualdade, é preciso se afirmar como diferente; por outra via, a diferença entre os grupos não contempla todas as diferenças necessárias ao reconhecimento do indivíduo enquanto sujeito singular. Paradoxo semelhante se observa na proposição entre universal e particular, quando a incidência de uma mensagem performativa desloca as características de universalidade que mantêm um grupo coeso e faz um furo sobre o caráter identitário do grupo.

A questão central debatida pelos gender studies é justamente prescindir de um sujeito universal, o que resultaria numa diferença que não fosse sinônimo de desigualdade. Uma diferença autônoma, por assim dizer. Os corpos abjetos, na perspectiva butleriana, são exemplo de como o singular faz vacilar a norma e amplia contingencialmente

5 “Cette nomination se constitue en tant que telle à partir d'un processus de désidentification du sujet avec les noyaux condensateurs de jouissance au coer de ses symptômes, et ici, elle opère dans le sens exactement opposé aux identifications qui se produisent à partir de la jouissance sexuelle promue par les cultures queer". 
o limite do humano. É o próprio estranhamento - fazendo menção ao termo utilizado por Freud no texto $O$ Estranho - que emerge em sua vertente real e atravessa o universo simbólico enlaçado sobre uma imagem universal de homem. Por isso os transgêneros, travestis, assexuados, intersexos e toda uma diversidade de formas da sexualidade humana causam angústia no Todo social, que prefere mantê-los apartados, invisíveis, fora do olhar, a ter que enxergar esses corpos estranhos, queer, que encarnam a perspectiva tangível do objeto $a$.

Nomear esses sujeitos, no entanto, incorre na repetição própria ao simbólico: eles passam a ser representados dentro de uma norma, como grupo com identidade própria, e passam a adquirir qualidades. Tais qualidades, sendo da ordem do universal, acabam atropelando as singularidades que venham surgir dentro desse próprio grupo que era outrora submetido à inexistência. Os estudos de gênero parecem atentos a esse paradoxo, ao qual Judith Butler tenta responder com o conceito de performatividade de gênero.

\section{Considerações finais}

Através do desenvolvimento da noção de performatividade na psicanálise e nos estudos queer, foi possível notar que a questão da nomeação dos corpos sexuados se depara com um impasse. Se nomear gênero é algo contra o qual os próprios estudos de gênero têm lutado, na tentativa de fazer as formas de sexualidade ganharem expressão por outros modos que não os da identidade, aproximando-as da atuação performática, por outro lado é preciso reconhecer a validade simbólica dos nomes como um meio de garantir a visibilidade dos corpos abjetos.

Paradoxalmente, pode-se dizer que o feminismo queer se encontra apoiado sobre o exame da subversão do movimento coletivo que acaba manifestando seu projeto político sobre a mesma estrutura opressora de poder. A reivindicação dos teóricos queer é justamente depurar o sujeito de uma identidade grupal, em que o saber significante impera sobre o corpo, estando este capturado numa lógica universal, para fazê-lo se sustentar na singularidade daquilo que compõe - muitas vezes estranhamente - sua sexualidade. 
Já para a psicanálise, a nomeação revela o impossível. Isso porque o real, onde a experiência sexual faz sua marca, é algo que resiste à atividade da escrita. Como nos fala Lacan, o real é o que "não pára de não se escrever" (2008/1972-1973, pág. 101). Por isso vale apostar, enquanto saída para esse, digamos, mal-estar da significação, naquilo que Pinto definiu como uma "existência indeterminada" (Pinto, 2008, pág. 114). Tal existência não significa que o sujeito está inundado no campo do real, sem qualquer determinação e por isso pode vir a ser qualquer coisa. Pinto nos lembra que a escritura que constitui o sujeito está entre o necessário e o contingente, portanto, a ação do significante sobre o corpo resulta em uma imbricação singular.

Uma análise, ao se apoiar na associação livre, é o convite à "possibilidade de poder ser infinitamente diferente daquilo que se apresenta como sendo da ordem da necessidade" (Pinto, 2008, pág. 114). A singularidade do sujeito depende disto: que ele faça emergir seu desejo, através do ato, deslocando-se do determinismo significante e das exigências pulsionais que fazem dele refém da mestria do saber inconsciente. A força do ato performativo se encontra justamente aí.

\section{Referências}

Ambra, P. E. S. (2017). Das fórmulas ao nome: bases para uma teoria da sexuação em Lacan [Tese de Doutorado, Instituto de Psicologia, Universidade de São Paulo]. https:/ / teses.usp.br/teses/disponiveis/47/47134/ tde-12012018-174515/pt-br.php

Butler, J. (2016/1990). Problemas de gênero. Feminismo e subversão da identidade (Rento Aguiar, trad.). Civilização Brasileira.

Butler, J. (2015). Relatar a si mesmo: crítica da violência ética (Rogério Bettoni, trad.). Autêntica.

Butler, J. (2018). Quadros de guerra: Quando a vida é passível de luto? (Sérgio Tadeu Lamarão e Arnaldo Marques da Cunha, trad.). Civilização Brasileira.

Butler, J. (2018). Os atos performativos e a constituição do gênero: um ensaio sobre fenomenologia e teoria feminista (Jamille Pinheiro Dias, trad.). Caderno de Leituras, (78). http:/ / chaodafeira.com/wp-content/uploads/2018/06/caderno_de_leituras_n.78-final.pdf. 
Fajnwaks, F. (2015). Lacan et ler théories queer: malentendus et méconnaissances. In C. Leguil, C., F. Fajnwaks (orgs), Subversion Lacanienne des Théories du Genre (págs. 19-46). Éditions Michèle.

Freud, S. (1996/1916-1917). Conferências introdutórias sobre psicanálise. Conferência XVIII: fixação em traumas - o inconsciente. In J. Strachey (Ed.), Edição Standard Brasileira Das Obras Psicológicas Completas De Sigmund Freud, (vol. XVI, págs. 281-292).

Freud, S. (2019/1919). O infamiliar [Das Unheimliche]. In Ernani Chaves, Pedro Heliodoro Tavares (Trads.), Obras Incompletas de Sigmund Freud (vol. 8, págs. 27-126). Autêntica.

Hall, S. (2006). A identidade cultural na pós-modernidade (Tomaz Tadeu da Silva, Guaracira Lopes Louro, trads.). DP\&A.

Lacan, J. (1998/1957). A instância da letra no inconsciente ou a razão desde Freud. In J. Lacan, Escritos (Vera Ribeiro, trad.), (págs. 496-536). Zahar.

Lacan, J. (1998/1958). A significação do falo. In J. Lacan, Escritos (Vera Ribeiro, trad.), (págs. 692-703). Zahar.

Lacan, J. (1998/1966). A ciência e a verdade. In J. Lacan, Escritos (Vera Ribeiro, trad.), (págs. 869-892). Zahar.

Lacan, J. (2008/1972-73). Seminário, livoro 20: Mais, ainda. Zahar.

Miller, J.-A. (2003). O rouxinol de Lacan. Carta de São Paulo, 10(5), 18-32. http://ea.eol.org.ar/03/pt/textos/txt/pdf/el_ruisenor.pdf.

Miskolci, R. (2011). Não ao sexo rei: da estética da existência foucaultiana à política queer. In L. A. De Souza, T. T. Sabatine e B.R. de Magalhães (orgs.), Michel Foucault: sexualidade, corpo e direito (págs. 47-68). Cultura Acadêmica.

Pinto, J. M. (2008). O desejo do analista: o sujeito, o necessário e a contingência. In J. M. Pinto, Psicanálise, feminino, singular (págs. 109-122). Autêntica.

Pinto, J. M. (2008). Psicologia das massas e análise do Eu: uma teoria do final de análise? In J. M. Pinto, Psicanálise, feminino, singular (págs. 41-54). Autêntica.

Safatle, V. (2012). Grande Hotel Abismo: por uma reconstrução da teoria do reconhecimento. Editora WMF Martins Fontes.

Safatle, V. (2015). Dos problemas de gênero a uma teoria da despossessão necessária: ética, política e reconhecimento em Judith Butler (Posfácio). In J. Butler, Relatar a si mesmo: crítica da violência ética (Rogério Bettoni, trad.), (págs. 173-196). Autêntica.

Scott, J. W. (2005). O enigma da igualdade. Revista Estudos Feministas, 13(1), 11-30. https://www.scielo.br/scielo.php?script=sci_art text\&pid=S0104-026X2005000100002 
Spitzner, M. (2017). Judith Butler e Michel Foucault: considerações em torno da performatividade, do discurso e da constituição do sujeito. Web Revista Discursividade, (19), s.p. http://www.discursividade. cepad.net.br/atual/Arquivos/spitzer.pdf

Teixeira, A. (2010). O alicerce contingente do Universal. In Revista Estudos Lacanianos, III (5), 127-135.

Vieira, M. A., \& Barros, R. R. (2015). Mães. Subversos. 